\title{
Çivi İmalatı Yapan Bir İşletmede Gürülttü Analizi
}

\author{
Ergun Ateş*1, Ebru Arabacioğlu ${ }^{1}$ \\ ${ }^{1}$ Balıkesir Üniversitesi, Mühendislik Fakültesi, Makine Mühendisliği Bölümü
}

20.12.2018 Geliş/Received, 14.03.2019 Kabul/Accepted

\section{Özet}

İmalat işletmelerinde farklı alanlar ve ürünler konu olsa da, üretim için birçok makina ve ilgili elemanlar birlikte çalışmaktadır. Ortama yayılan sesler, kanun ve yönetmeliklerde belirtildiği şekilde çalışanın tahammül edemediği değerlere ulaşabilir. Bu durum birey için normal dış1, rahatsızlık veren ve düzeyi azdan çoğa farklı dış etkiler olup, maruz kalma süreleri de oldukça önemlidir. Bu çalışmada çivi imalatı yapan bir işletmede, çalışanlar üzerine gürültünün etkisini belirleyebilmek için gürültü ölçümleri yapılmıştır. İşletmede makine ünitesinde en düşük-en yüksek ölçüm değerleri 86,1-101,6 dB(A) olarak elde edilmiştir. Bu bölgeden alınan yüksek gürültü seviyesi nedeniyle, çalışan sağlığı üzerinde olumsuz etkileri olacağı açıktır. İsyerinde alınan önlemlere ek olarak, yasa ve yönetmeliklerde belirtilen diğer önleyici önlemlerin alınmasının yararlı olacağı söylenebilir.

Anahtar Kelimeler: iş güvenliği, çalışan sağlığı, gürültü, çivi imalatı

\section{Noise Analysis at a Nail-Manufacturing Company}

\begin{abstract}
Although different areas and products are involved in manufacturing companies, various machinery and equipment work together in production processes. Noises released into the environment can reach values that the employees may find intolerable as stated in the laws and regulations. While that in itself may generate unusual external impacts that cause discomfort for an employee on a spectrum ranging from mild to severe, the duration of exposure is also very important. For the purposes of this study, noise measurements were made in a nail-manufacturing company to determine the effect of noise on the employees. The lowest-highest measurement values recorded in the company's machinery unit were 86,1$101,6 \mathrm{~dB}(\mathrm{~A})$. It is obvious that due to the high noise level taken from this region, it will have negative effects on employee health. In addition to the measures taken in the workplace, it can be said that taking other preventive measures mentioned in laws and regulations will be beneficial.
\end{abstract}

Keywords: occupational safety, employee health, noise, nail manufacturing

\section{Giriş}

İmalat işlemleri yapan işletmelerde, o an çalışmakta olan veya rutin çalışanların yanında devreye giren ve çıkan makinaların da birlikte çalışması sebebiyle, ortama yayılan gürültünün

*Sorumlu Yazar (Corresponding Author): Ergun Ateş

(e-posta:ergunates@gmail.com) 
çalışan sağlığı üzerinde olumsuz etkiler oluşturduğu bilinmektedir. Zamana bağlı olumsuz etkinin daha da arttığı literatürde de açıklanmıştır.

Gürültünün kişi üzerinde etkisi farklı olsa da akustik travma, uyku problemi, kardiyovasküler sistem ve performans üzerinde olumsuz etkiye sebep olabilir (Alberti, 1997; Porter, 1998; Wallace, 1998). Yapılan bir çalışmada (Arıtan ve Tümer, 2017); Afyonkarahisar, İscehisar ilçesinde doğaltaş fabrikasında Denizli Traverteni kesiminde gürültü ölçümü yapılmıştır. Sonuçta işletmenin bazı bölgelerinde ortam şartlarının gözden geçirilmesi gerektiği belirtilmiş ve "çalışanların gürültüye uzun süre maruz kalmaması için uyarıcı levha ve kulak tıkac1/kulaklık gibi” alınabilecek önlemler açıklanmıştır (Arıtan ve Tümer, 2017). Tarım makinaları üretimi yapan bir firmada çalışan alet, cihaz ve makinaların yüksek gürültü değerleri oluşturduğu belirlenmiştir. Fabrikada rutin çalışan makinalar nedeniyle gürültünün kararlı ve sürekli olması çalışanlar üzerinde olumsuz etki oluşturmaktadır. İşyerinde risk olarak görülen gürültü seviyesi değerleri ve çalışanların işitme sağlığı için koruyucu önlemlerin alınması gereği belirtilmiştir (Ateş ve Alagöz, 2018). Bir konfeksiyon firmasında yapılan risk etmenleri değerlendirilmesinde gürültü ölçümlerinin sınır değerlerine bazı bölümlerde yakınlaştığı tespit edildiğinde, çalışanların gürültü kontrol yönetmeliğine göre eğitilmeleri gereği açıklanmıştır (Dedeler, 2008). İmalat işlemlerinde gürültü değerleri $85 \mathrm{~dB}(\mathrm{~A})$ üzerinde olduğunda çalışan sağlığı adına önlem alınması gerekmektedir (Darpe, 2015; OSHA, 2016). Tekstil iş kolunda çalışan iş̧̧ilerde gürültüye bağlı oluşan işitme kaybı ve bu kaybı etkileyen faktörler, bazı kan parametreleri ile ortam gürültü düzeyi arasındaki ilişki incelenmiştir. Bu çalışmada $85 \mathrm{~dB}(\mathrm{~A})$ üzeri gürültülü ortamda çalışanlarda artan yaşa göre gürültüye bağlı işitme kaybının arttığı görülmüştür (Erdoğan, 2016). Fabrikalarda rutin çalışan makinalar kararlı gürültüye sebep olmaktadır. Gürültü düzeyi dağılımı çalışma şekline bağlı olarak dalgalı, kesikli, darbe şekillerinde olabilmektedir. Dolasıyla birey üzerine etkileri farklı olmaktadır (Güler ve Çobanoğlu, 1994). Yapılan başka bir çalışmada, küçük ve orta ölçekli metal malzeme imalatı iş yerlerinde gürültü incelenmiştir. Bu çalışmada parametreler; 3 iş alanı, 3 fabrika ve 40 imalat işlemi için 250 nokta olarak belirlenmiştir. İmalat işlemlerinde ses kaynaklarından frekanslar veri olarak alınmıştır (Kim ve ark., 2013). Kapalı bir alanda hasat sonrası kullanılan mikser, selektör ve çekiçli yem kırma makinasının çalıştırıldığı alanlarda gürültü ölçümü yapılmıştır. Bu çalışmada gürültü düzeyi uyarı sınırı $85 \mathrm{~dB}(\mathrm{~A})$, gürültü düzeyi tehlikeli sınırı ise $95 \mathrm{~dB}(\mathrm{~A})$ değeri alınmıştır. Çekiçli yem kırma makinasının gürültü düzeyi $98 \mathrm{~dB}(\mathrm{~A})$ değeri ölçülmüştür ve ölçülen değerin yüksek olmasından dolayı önlemler alınmasına ve gürültü çıkaran makinanın daha az gürültü çıkaran bir makine ile değiştirilmesi kararı alınmıştır (Özgüven, 2012). "Çalışanların Gürültü İle İlgili Risklerden Korunmalarının Dair Yönetmeliğin 8. Maddesine Göre; Maruziyetin Önlenmesi ve Azaltılması Sorumluluğu İşverene Aittir", demektedir. Yönetmeliğin 5.maddesine göre LEX, 8 saat olmak üzere maruziyet değerleri "en düşük $80 \mathrm{~dB}(\mathrm{~A})$, en yüksek $85 \mathrm{~dB}(\mathrm{~A})$, sınır değeri ise $87 \mathrm{~dB}(\mathrm{~A})$ )" olarak belirlenmiştir (Anonim, 2013). Tekstil işletmesinde çözgü sarma, ağızlık açma, atkı atma, tefe vurma ve kumaş sarma makinalarından gürültü ölçümleri, makinalardan $1 \mathrm{~m}$ uzaklıktan ve $1 \mathrm{~m}$ yükseklikten alınmıştır. Ölçümler, gürültü seviyesinin $85 \mathrm{~dB}(\mathrm{~A})$ üzerinde olduğunu göstermiş ve bunun azaltılması için çözüm üretilmesi gereği açıklanmıştır (Sağbaş ve ark., 2008). Küçük ve orta ölçekli döküm, dövme endüstrisinde denek olarak alınan erkek işçiler ile yapılan ölçümler sonucunda 90 dB(A)'dan daha yüksek gürültü değerleri alınmıştır. Gürültü ile birlikte 1sı maruziyeti de incelendiğinde, 60-72 saat/hafta çalışma sürelerinin yüksek olduğu ve koruyucu önlem alınması gereği açıklanmıştır (Singh ve ark., 2010). Bir başka çalışmada incelenen tesis, iplik, indigo, haşıl, terbiye, kalite, dokuma ve sevkiyat olarak 7 ana bölümden oluşan, Kayseri ilinde faaliyet gösteren bir tekstil fabrikasıdır. Bu çalışmada, dokuma bölümünde maruz kalınan gürültü değerlerini belirlemek üzere, ölçümler 4 noktada yoğun saatlerde yapılmış ve 10 iş gününde tekrarlanmıştır. Elde edilen değerler incelendiğinde, belirlenen ortalama eşdeğer gürültü düzeyleri 73,4 ile 
94,4 $\mathrm{dB}(\mathrm{A})$ aralığında değişmektedir. Ölçümler dokumanın bazı bölümlerin de aşırı gürültüye maruziyetini göstermiş ve alınabilecek tedbirler açıklanmıştır (Soylu ve Gökkuş, 2016). Ekonomik İşbirliği ve Kalkınma Örgütü'nün (OECD) 1996 yılı raporuna göre gürültünün rahatsızlık verme başlangıcı 55-60 dB(A), rahatsızlığın belirgin artması 60-65 dB(A) ve davranış biçiminde engel oluşma seviyesi $65 \mathrm{~dB}(\mathrm{~A})$ üzeri olduğu açıklanmıştır (Anonim, 2019). Başka bir imalat firmasında üretim tezgahlarının çalışmaları anında gürültü ölçülmüşsür. Bu çalışmada makinelerin tek çalışmalarına göre, birlikte çalışmaları daha büyük gürültü değerleri vermiştir. Bazı makinelerin gürültülerinin yönetmelikte verilen değerleri aştığ1 gözlenmiştir. Gürültü açısından spiral 92,8 -97,6 dB(A) ile en yüksek değere sahiptir. Bu durumda, koruyucu önlemlerin alınması önerilmiştir (Yavuz ve ark., 2016; Özce ve ark., 2018). Nijerya'da genelde ABD, Hindistan veya Çin'den ithal edilmekte olan çivi makinelerinin, yapılan tasarımın; performans, çevresel faktörler, bakım, estetik / ergonomi, boyut ve ağırlık, güvenlik ve maliyet açısından teknik ve ekonomik bir değerlendirmesi yapılmıştır. Sonuçta ithal edilen makinanın bedeli ile tasarımı kıyaslandığında, ithale nazaran 6.29 kat daha ucuza üretilebileceği belirlenmiştir (Olala and Katiku, 2012).

Dünya Bankası tarafından yayınlanan bir uygulama el kitabı çevresel etkenler bölümünde, yüksek ve aşırı gürültü seviyelerinin insan sağlığı üzerine olumsuz etkileri incelenmiş, ülkelerden bazı örneklere de yer verilerek öncelikle problemlerin tespiti, devamında azaltılmasına yönelik bir yönetim sistemi açıklanmıştır (Angeletti ve ark., 2015). Bir çivi imalathanesinde yapılan gürültü ölçümünde $1,83 \mathrm{~m}$ 'den, $111 \mathrm{~dB}(\mathrm{~A})$ değeri elde edilmiştir (Weinger ve ark., 2010).

Çalışan sağlığı, üretimin verimi açısından oldukça önemlidir. Bazı üretim alanları için birçok araştırma yapılmıştır. Bunların içerisinde, ülkemizde bu çalışmada seçilmiş olan bir çivi imalathanesinde yapılan gürültü analizine benzer bir çalışma rapor edilmemiştir. Bu çalışmada çivi imalatı yapan bir işletmede, çalışanlar üzerine gürültünün etkisini belirlemek amaçlanmiştır

\section{Materyal ve Yöntem}

İşletmede gürültü ölçümleri için A, C, ve Z frekanslarında (23-137 dB(A)) ölçüm yapabilen, EN 60651 standardına uygun, sinıfı Type-1 olan (SC310 CESVA Sound Level Meter, Barcelona, Spain) bir gürültü ölçüm cihazı kullanılmıştır. Cihaz gerçek zamanlı olarak verileri kaydedebilir ve bilgi ekran üzerinden direkt okunabilir. Cihaz, "Studio Capture" yazılımı aracılığı ile bilgisayara da bağlanabilir. Bu halde veriler anlık bilgisayara kaydedilebilir, bilgisayardan izlenebilir ve verilerle ilgili düzenlemeler de yapılabilir özelliktedir (Cesva, 2019).

Çalışmada, her bir ölçüm 3 dakika süreli olup en az 3 ölçümün ortalama değeri dB(A) olarak alınmıştır. Ölçüm yapılırken dikkat edilen diğer bir konu; planlanan ölçüm noktalarının tümü bitirildikten sonra, ikinci ölçümler ve devamında da üçüncü ölçümler yapılmıştır. Bu sayede birinci ölçüm sonrası en az bir saat geçmiş, ikinci ölçüm sonrası yine en az 1 saat sonrasında üçüncü ölçümler alınmıştır. Bu şekilde elde edilen ölçüm sonuçlarının, çalışmayı daha doğru açıklayabileceği düşünülmüştür. Farklı günlerde olmak üzere toplam olarak onbir işletme ziyareti gerçekleştirilmiştir. Bir çalışanın diğer çalışana yüksek sesle seslenmesi, içerde forklift sesine ek olarak operatörün korna çalması, herhangi bir ağır parçanın yere düşmesi, sık tekrar etmeyen uygulamalar, bakım nedeniyle veya yönetim tarafından imalata ara verilmesi, gibi işletmede yaşanan olağan dışı durumların etkisini azaltmak için (bazen ölçüm anında yukarıda bahsedilen durumlarla karşılaşıldığından) ölçümler üç defadan fazla sayıda tekrarlanmıştır. Yukarıda verilen istisnai durumlar anlık darbeli gürültü seviyelerini arttıran 
etkenler olarak da gösterilebilir. Bu durum fabrika alanının herhangi bir yerinde rastgele olabilmektedir. Her bir ziyarette farklı makinelerin çalışıyor olması, fabrikada yaşanan rutin bir durumdur.

İşletme yerleşim olarak 3 birimden oluşmaktadır (Şekil 2.1). Bunlar, girişte üretimin yapıldı̆̆ "makina ünitesi", makina ünitesinden tamamen ayrılmış olan ve ana girişin uzağında kalan "hazırlık ve üretim sonrası" bölüm ve "idari bölümler" şeklindedir. İdari bölümler 2. katta olup bu birimin altında (Şekil 2.1'de A, B, C olarak tanımlanmıştır) sırasıyla A; WC ve takımhane, B; yemekhane ve laboratuvar, C; tartı, tamirhane, malzeme deposu yer almaktadır.

Şekil 2.1'de verilen yerleşim planı üzerinde 000'dan başlayarak 023'e kadar verilen numaralar tüm işletmede ölçüm alınan noktaları göstermiştir. İşletmede ölçüm alınırken makina ünitesindeki tüm makina numaraları karşısındaki bütün ölçüm numaraları aynı anda çalışır durumda değildir. İşletme, ölçüm için farklı zamanlarda ziyaret edilmiş olsa da, iş planına göre belirli makinalar çalışıyor olduğundan, işletmenin rutinine kesinlikle engel olunmamıştır. Bu fabrikanın doğal çalışma seyrinde çalışanlara olan gürültü maruziyetini doğru belirleyebilme adına da önemlidir. Şekil 2.1 ve Çizelge 2.1 'den görüleceği üzere ölçüm noktasından ölçüm alınırken, çalışmakta olan makinalara göre "merkezi bir ölçüm noktası" almaya özen gösterilmiştir. Makinaların birbirlerine göre boyutları, tipleri, özellikleri farklıdır. Bu durum nedeniyle ölçüm yapılan seviyeler, "makinaların hareketli elemanlarının olduğu seviyeler olarak" dikkate alınmıştır. Ölçüm seviyeleri ise Çizelge 2.1'de ilgili sütunda, her bir ölçülen noktaya göre ayrı ayrı verilmiştir. Fabrika yerleşimi Şekil 2.1'de verildiği gibi 1/1 ölçekte aynı olup, alan ölçüleri ise $39,02 \times 30,3 \mathrm{~m}^{2}$ 'dir.

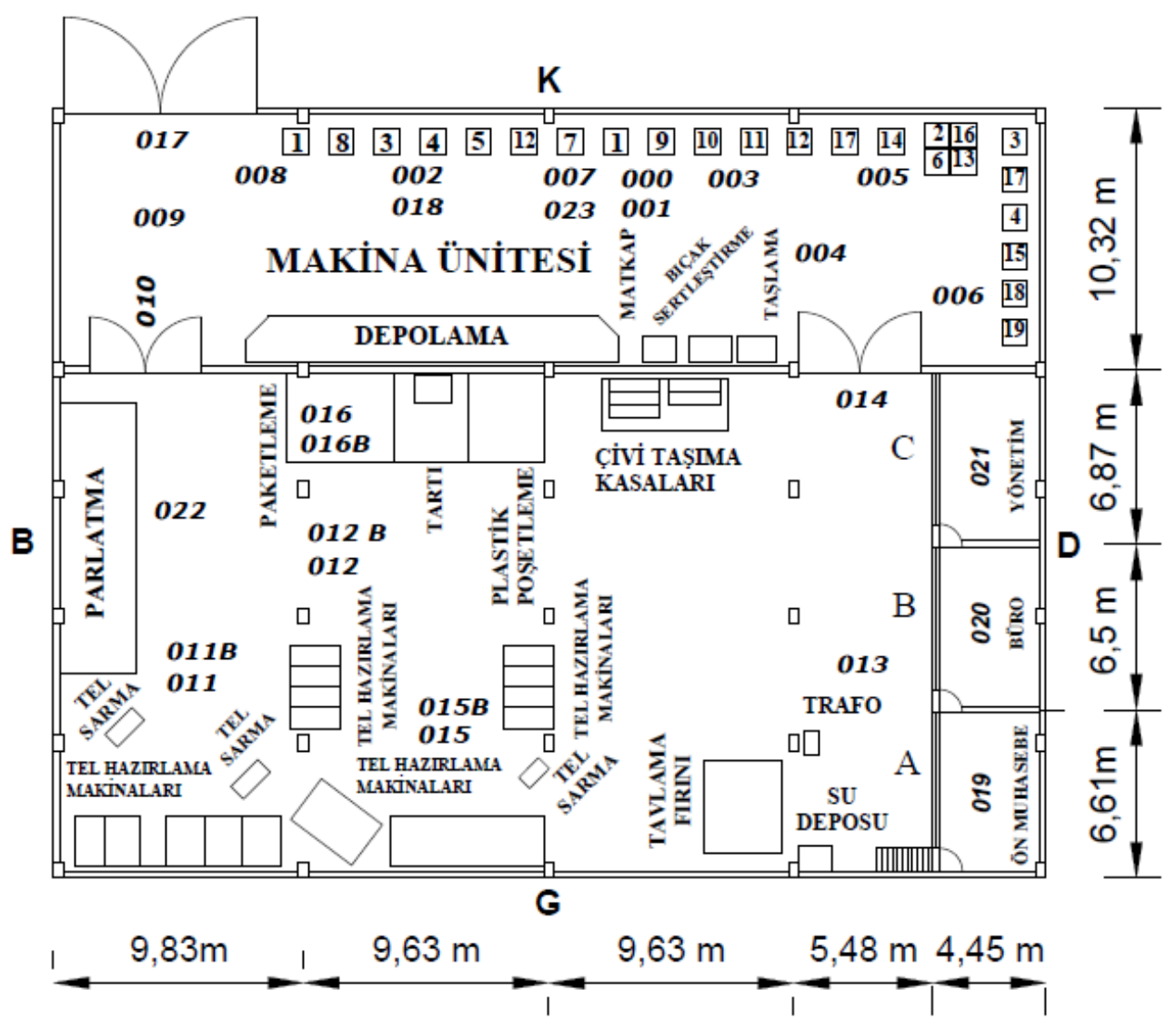

Şekil 2.1 Yerleşim planı ve ölçüm noktaları 
İdari bölümleri oluşturan ön muhasebe, büro ve yönetim birimleridir. Burada giriş için tek bir kapı mevcut olup genelde daima kapalıdır ve gürültü kaynağı olan makina ünitesine en uzak noktadadır. Makine ünitesinin çalışıyor olması anında, arka bölümde yer alan idari büroların, içerisinde genelde gürültü kaynaklı olumsuz bir etki hissedilmemiştir. Bu nedenle ilk etapta idari bölümlerden herhangi bir ölçüm $(019,020,021)$ alınmamıştır. Fakat bu durum makine ünitesi çalışıyor iken, arka bölümde çalışan makineler de olduğunda, farklılık göstermektedir. İdari bölümlerde de oldukça belirgin ve çalışanlar için zamanla rahatsızlık yaratabilecek gürültü seviyeleri de oluştuğu belirlenmiştir. Bu nedenle arka bölüme ait olan gürültü ölçüm noktalarının yanında yazılan B sembolleri ile verilen gürültü değerleri, aynı anda (makine ünitesi çalışıyor durumdayken) ilave olarak arka bölümdeki makineler de çalışıyorken, aynı ölçüm noktalarından alınan gürültü değerlerini göstermektedir.

Çizelge 2.1 İşletmeden alınan ölçümlerde aktif makinalar ve ölçüm yerleri

\begin{tabular}{|c|c|c|c|c|c|}
\hline \multicolumn{6}{|c|}{ Makine Ünitesi Çalışmasında Ölçüm Değerleri } \\
\hline \multirow{2}{*}{ Ölçüm Numarası } & \multirow{2}{*}{ Aktif Makinalar } & \multirow{2}{*}{ Ölçüm Yeri } & \multicolumn{2}{|c|}{ Ölçüm Mesafesi (m) } & \multirow{2}{*}{$\begin{array}{c}\text { Ortalama } \\
\text { Değer } \\
\text { dB(A) }\end{array}$} \\
\hline & & & Yere & Duvarlara & \\
\hline 000 & 3,6 & (3) ve (6) arası & 1,00 & $\mathrm{~K} 2,25$ & 99,0 \\
\hline 001 & $3,4,6$ & $(3,4)$ ve $(6)$ aras 1 & 1,00 & $\mathrm{~K} 2,25$ & 101,4 \\
\hline 002 & $3,4,6$ & (3) ve (4) arası & 1,00 & $\mathrm{~K} 2,25$ & 101,6 \\
\hline 003 & $3,4,7,10,14,17,18$ & (10) önü & 1,00 & $\mathrm{~K} 2,25$ & 100,5 \\
\hline 004 & $3,4,7,10,14,17,18$ & Kisa hat ortası & 1,00 & $\mathrm{~K} 5,16$ - D9,93 & 95,1 \\
\hline 005 & $3,4,7,10,14,17,18$ & (14) önü & 1,00 & $\mathrm{~K} 2,25$ & 95,1 \\
\hline 006 & $3,4,7,10,14,17,18$ & (18) önü & 1,00 & $\mathrm{D} 2,25$ & 95,6 \\
\hline 007 & $3,4,7,10,14,17,18$ & (7) önü & 1,00 & $\mathrm{~K} 2,25$ & 95,2 \\
\hline 008 & $3,4,7,10,14,17,18$ & (1) sol yan & 1,00 & $\mathrm{~K} 2,25$ & 94,4 \\
\hline 009 & $3,4,7,10,14,17,18$ & Giriş-1. arka giriş ortası & 1,00 & $\mathrm{~K} 5,16-\mathrm{B} 4$ & 92,5 \\
\hline 010 & $3,4,7,10,14,17,18$ & 1. arka giriş ortası & 1,00 & B4 & 91,4 \\
\hline 011 & $3,4,7,10,14,17,18$ & 1. giriş karşı ortası & 1,00 & G9,86 - B4,92 & 94,7 \\
\hline 012 & $3,4,7,10,14,17,18$ & Tel hazırlama, paketleme arası & 1,00 & $\mathrm{G} 13,11-\mathrm{B} 12,42$ & 89,5 \\
\hline 013 & $3,4,7,10,14,17,18$ & Ofis önü & 1,00 & D7,19 - G8,61 & 86,1 \\
\hline 014 & $3,4,7,10,14,17,18$ & 2. arka giriş ortası & 1,00 & $\mathrm{D} 7,19$ & 92,6 \\
\hline 015 & $3,4,7,10,14,17,18$ & Tel hazırlama ortası & 1,00 & $\mathrm{G} 6,61-\mathrm{B} 14,65$ & 90,6 \\
\hline 016 & $3,4,7,10,14,17,18$ & Paketleme önü & 1,00 & $\mathrm{~A} 5,25-\mathrm{B} 12,5$ & 87,1 \\
\hline 017 & $3,4,7,10,14,17,18$ & Giriş kapısı ortası & 1,00 & $\mathrm{~K} 0,00-\mathrm{B} 4,00$ & 91,7 \\
\hline 018 & $3,4,7,10,14,17,18$ & (3) ve (4) arası & 1,00 & $\mathrm{~K} 2,25$ & 97,2 \\
\hline
\end{tabular}

Arka bölüm devreye girdiğinde 019, 020, 021, 022, 023, 011B, 012B, 015B, 016B ölçümleri yapılmış ve bu değerler Çizelge 2.2'de verilmiştir. Şekil 2.1'de gürültü ölçümlerin de eğikkalın olarak verilen ölçüm numaraları sembolleri yanına ilave edilen büyük harf B simgesi, aynı noktadan alınan ikinci ölçüm olduğunu göstermektedir. Şekil 2.1'de bu semboller verilmiştir. Şekil 2.1'de fabrika yerleşim planı dışında sembol olarak gösterilen K, D, G, B harfleri ise saat ibreleri yönünde olmak üzere, Çizelge 2.1 'de ve Çizelge 2.2 'de mesafe sütununda duvara olan uzaklıkların önündeki harfler olarak verilmiştir. Bu gösterimde "ölçüm yerinin" yakın olduğu duvarlara olan uzaklıkların belirtilmesi tercih edilmiştir. Çizelgelerdeki mesafe sütununda verilen diğer bir bilgi de ölçüm anında yerden olan yükseklik bilgisidir. Yerden olan yüksekliğin belirlenmesindeki durum, yukarıda bahsedildiği üzere gürültüye sebebiyet 
veren, farklı boyutlardaki makinaların hareket eden elemanlarının olduğu merkezi bir noktadir.

Çizelge 2.2 İşletmeden alınan ölçümlerde aktif makinalar ve ölçüm yerleri

\begin{tabular}{|c|c|c|c|c|c|}
\hline \multicolumn{6}{|c|}{ Arka Bölüm Çalışmasında Ölçüm Değerleri } \\
\hline \multirow[b]{2}{*}{ Ölçüm Numaras1 } & \multirow[b]{2}{*}{ Aktif Makinalar } & \multirow[b]{2}{*}{ Ölçüm Yeri } & \multicolumn{2}{|c|}{ Ölçüm Mesafesi (m) } & \multirow{2}{*}{$\begin{array}{c}\text { Ortalama } \\
\text { Değer } \\
\text { dB(A) }\end{array}$} \\
\hline & & & Yere & Duvarlara & \\
\hline 019 & $\begin{array}{l}3,9,7,12 \\
011 \mathrm{~B}, 015 \mathrm{~B}\end{array}$ & İdari bölüm. & 0,75 & $\mathrm{D} 2,23-\mathrm{G} 3,30$ & 65,7 \\
\hline 020 & $\begin{array}{l}3,9,7,12 \\
011 \mathrm{~B}, 015 \mathrm{~B}\end{array}$ & İdari bölüm. & 0,75 & $\mathrm{D} 2,23-\mathrm{G} 9,86$ & 66,4 \\
\hline 021 & $\begin{array}{l}3,9,7,12 \\
011 \mathrm{~B}, 015 \mathrm{~B}\end{array}$ & İdari bölüm. & 0,75 & $\mathrm{D} 2,23-\mathrm{A} 4,43$ & 68,8 \\
\hline 022 & $\begin{array}{l}3,4,9,12 \\
\text { 011B, 015B } \\
\text { 022Parlatma }\end{array}$ & Parlatma önü. & 1,45 & $\mathrm{G} 13,11-\mathrm{B} 4,00$ & 90,1 \\
\hline 023 & \begin{tabular}{|l}
$3,4,9,12$ \\
011B, 015B \\
022Parlatma \\
\end{tabular} & (7) önü. & 1,00 & $\mathrm{~K} 2,25$ & 95,6 \\
\hline 011B & $\begin{array}{l}3,4,9,12, \\
\text { 011B, 015B, } \\
\text { 022Parlatma }\end{array}$ & 011B İşaretli yer. & 1,00 & G9,86 - B4,92 & 96,1 \\
\hline 012B & \begin{tabular}{|l|}
$3,4,9,12$ \\
011B, 012B, 015B \\
022Parlatma \\
\end{tabular} & 012B İşaretli yer. & 1,00 & $\mathrm{G} 13,11$ - B12,42 & 87,9 \\
\hline 015B & \begin{tabular}{|l|}
$3,4,9,12$ \\
011B, 015B \\
022Parlatma \\
\end{tabular} & 015B İşaretli yer. & 1,00 & G6,61 - B14,65 & 90,2 \\
\hline 016B & $\begin{array}{l}3,4,9,12 \\
\text { 011B, 015B, 016B, } \\
\text { 022Parlatma }\end{array}$ & 016B İşaretli yer. & 1,00 & $\mathrm{~A} 5,25-\mathrm{B} 12,5$ & 89,9 \\
\hline
\end{tabular}

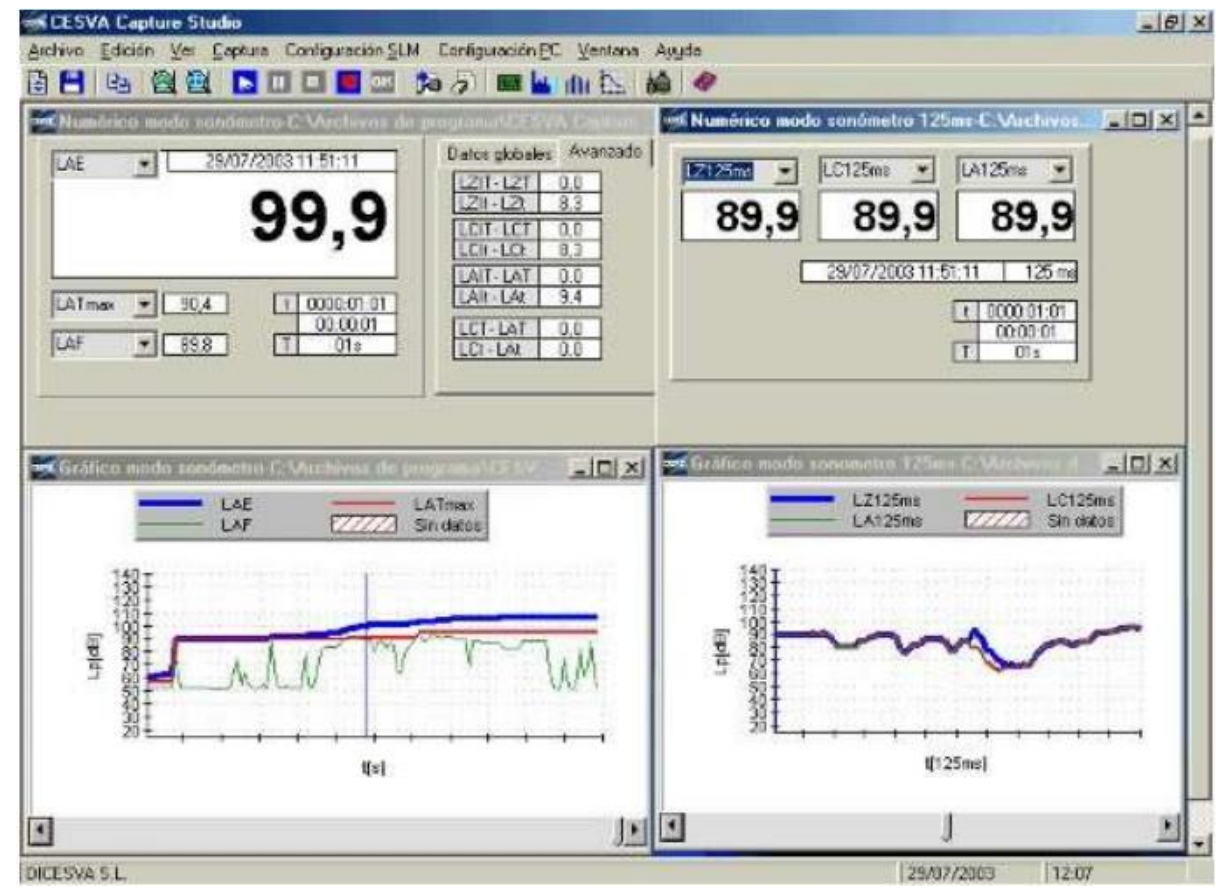

Şekil 2.2 Gürültü ölçüm ve kayıt cihazının yazılım aracılığıyla veri kaydı (Cesva, 2019) 


\section{Araștırma Bulguları ve Tartıșma}

İşletmede 000 ile tanımlanmış olan "ölçüm numarası" karşılığı olan 3,6 numaralı makinalar (Şekil 2.1) çalışmakta iken ikisinin orta noktasından ölçüm yapıldığında $99 \mathrm{~dB}(\mathrm{~A})$ gibi yüksek bir gürültü seviyesi olduğu görülmüştür. Ölçüm numarası 001 ve 002 olan ölçümlerde çalışan makinalar 3,4,6 olup 001 ölçüm yeri çalışan tezgahların orta noktası olarak alınmış ve bunun ölçüm değeri 101,4 dB(A) ile yüksek bir gürültü seviyesi olduğu belirlenmiştir. Ölçüm numarası 002 olan ise o an 3 tezgah $(3,4,6)$ çalışıyor iken ve iki tezgah arası mesafe $1 \mathrm{~m}$ olup 3 ve 4 numaralı tezgah orta önünden 101,6 $\mathrm{dB}(\mathrm{A})$ olarak en yüksek gürültü seviyesi ölçülmüştür. Ölçüm numarası 003, 10 numaralı çalışan makine önünden alınmış olup aynı anda çalışan diğer makinalar 3, 4, 7, 14, 17, 18'dir. Ölçüm değeri 100,5 dB(A) ile yüksek bir gürültü seviyesi tespit edilmiştir (Çizelge 2.1).

Ölçüm numarası 004'den başlayarak 018'e kadar olan ölçümlerin tümünde aktif makinalar 3, 4, 7, 10, 14, 17 ve 18 şeklindedir. Bu ölçümlerde en düşük gürültü seviyesi 86,1 dB(A) ve en yüksek ise 97,2 dB(A) olmuştur. Gürültü ölçümünde, ölçüm alınacak noktanın tezgah önünden olması veya tezgahlara uzak olması arasında, gürültü seviyesinin yüksekten azalana doğru bir eğilimde olduğu belirlenmiştir. Herhangi bir tezgahın diğerine göre çalıştığı anda ortama yaydığı gürültü eşit değildir. Bu farklılık nedeniyle, birlikte çalışan makinalar olsa da, ortama yayılan gürültü seviyesinin çalışan makina sayısına bağlı olarak, artıyor ya da azalıyor şeklinde bir sonuç çıkarmak anlamsız olmaktadır. Ölçüm yeri numarası 004'den 018'e kadar olan aktif makinalar için alınan ölçüm sonuçlarının farklı olması nedeni olarak; ölçüm yerleri olarak makina önü veya uzak bir noktanın seçilmesi, tezgahların atölyedeki yerleşimleri ve çalışanların makinalarda çalışırken bulunma ihtimalleri olan bir noktanın seçilmiş olması gibi farklı hallerden kaynaklandığı söylenebilir. İlave olarak, her bir tezgahın montajından ölçümlerin yapıldığı ana kadar geçen süreçte, tezgahın yoğun kullanımı, dinamik hareketlerin yapılmasında rolü olan elemanların bakımlarının zamanında yapılıp yapılmaması, bakım düzenli yapılmış olsa dahi makina ömründeki uzayan sürelerin gürültüyü arttırdığı da söylenebilir. $\mathrm{Bu}$ açıklanan sebeplere göre ölçüm numarası 001 ve 002 olan ölçümlerde özellikle 6 numaralı makinanın yapısı itibari ile elde edilmiş olan yüksek gürültü seviyelerinin alınmasına neden olduğu söylenebilir (Çizelge 2.1).

Ölçüm numarası 002 ile çalışmadaki en yüksek gürültü seviyesi 101,6 dB(A) ve ölçüm numarası 001 ile çalışmadaki ikinci en yüksek gürültü seviyesi 101,4 dB(A) olarak elde edilmiştir. Ölçüm numarası 003 ile de üçüncü en yüksek gürültü seviyesi 100,5 dB(A) ile elde edilmiştir. Ölçüm numarası 000 olan ölçümde, 3 ve 6 numaralı aktif makinaların yine 99 $\mathrm{dB}(\mathrm{A})$ gibi yüksek bir gürültü değeri vermesi de, benzer sebepli olduğu söylenebilir (Çizelge 2.1).

Makina ünitesi bölümünde ölçüm numaraları 000'dan 010'a ve ilave 017 ve 018 ile toplam 13 ölçüm yeri gürültü seviyeleri en düşük ve en yüksek 91,4-101,6 dB(A) arasında ölçülmüştür ve çalışan sağlığı açısında yüksek risklidir. Hazırlık ve üretim sonrası bölümünde ise ölçüm numaras1 011'den 016'a kadar toplam 6 adet veri ile en düşük ve en yüksek 86,1-94,7 dB(A) arasında ölçülmüştür. Bu bölgenin de yine yüksek riskli olduğu söylenebilir.

Tesisteki çalışma alanları, ön makine ünitesi birimi, arka hazırlık birimi ve paketleme bölümü ve idari bürolar altındaki dinlenme ve depo birimi olmak üzere üç ana birimden oluşmaktadır. Makina ünitesinde yerleşimleri yapılan makinaların sayısı dikkate alındığında, ortama yayılan gürültü adına mevcut durumda makinalar arasındaki mesafelerin yeteri kadar büyük olmadığ 1 söylenebilir. Çalışan makinalar oldukça yüksek gürültü oluşturmaktadır ve bu makineler 
birbirlerine çok yakın olarak konumlandırılmıştır. Dolayısıyla aynı anda çalıştıklarında ortama yayılan gürültü seviyesi artmaktadır. Alan olarak mekan yeterli büyüklüktedir ve burada her bir makina olmak üzere bölgesel ses izolasyonu yapılmasının yararlı olacaktır. İlave olarak makina ünitesi mekanına özel bir yapısal ses izolasyonu da düşünülebilir. İkinci birim olan arka bölüm ise yeterli büyüklüktedir. Çalışan makinaların yerleşimleri, gürültü oluşsa da yeterli uzaklıkta olduğu söylenebilir ve kullanım ergonomisi açısından da yeterlidir. İdari büro alt katındaki bölümlerde (Şekil 2.1, A, B, C) yer alan tüm birimler ihtiyaç olduğunda kullanılmaktadır. Bu bölümlerin en ölçüleri 3,735 m'dir ve makine ünitesine uzak bir yerdedir. Çalışanların bu bölgede, çalışma anında olmaması sebebiyle bu bölgede ölçüm numarası 013 ve 014 olan noktalardan alınan ölçümler çalışmada yeterli görülmüştür. $\mathrm{Bu}$ ölçümlerden sırasıyla 86,1 dB(A); 92,6 dB(A) gürültü seviyeleri elde edilmiştir. $B$ ile kodlanan birim, çalışanların dinlenme odası olarak kullanılmaktadır. Mekan normal yapı malzemeleriyle inşa edilmiştir. Bu birimde çalışma anında yüksek gürültüye maruz kalan işçiler, periyodik dinlenme yapabilirler. Fakat mekanda gürültü önleme adına herhangi bir tedbir alınmadığı belirlenmiştir.

İşletmeden alınan ölçümlerde, (makine ünitesi çalışıyor halde iken) arka bölüm devreye girdiğinde gürültü seviyeleri ölçümü idari bölümden sirasıly 019, 020 ve 021 olmak üzere 65,7-68,8 $\mathrm{dB}(\mathrm{A})$ aralığında gürültü değerleri alınmıştır. Gürültü derecesi, 2. Derecedeki gürültüler kapsamında 60-95 $\mathrm{dB}(\mathrm{A})$ olup; kan basıncı artışı, kalp atışlarında ve solunumda hızlanma, beyin sıvısındaki basıncın azalması, ani refleksler vb. fizloyojik reaksiyonlar olmak üzere sağlık üzerine çeşitli etkileri olduğu açıktır. İdari bölümden alınan değerler başlangıç düzeyi kabul edilse dahi, zamana bağlı çalışanlar üzerine olumsuz etkisi olacağı söylenebilir.

Parlatma makinasında, üretilen çivilerin (bazı karışımlar ilavesiyle) makina haznesine atıldıktan sonra, haznenin belirli bir devir sayısı ile döndürülerek, çivilerin temizlenmesi ve parlatılması işlemi tamamlanmış olur. Parlatma işleminde makine kapağı kapatılmadığı durumda 101,9 dB(A) olarak yüksek bir gürültü değeri ölçülmüştür. Parlatma makinası mekan içerisinde darbeli gürültü oluşturan bir ünite olarak tanımlanabilir. İş güvenliği gereği, çalışma anında ön kapak daima kapatılmaktadır. Buna rağmen oluşan ortalama gürültü seviyesi değeri 90,1 dB(A) olmuştur. Çalışan sağlığ1 açısından bu değer 3. derece gürültü (90-120 dB(A)) olarak tanımlanır ve fizyolojik reaksiyonların yanında baş ağrılarına da sebep olabilir. Ölçüm numarası 023 olan ölçümde, makine ünitesinde aynı anda çalışan 4 makine ile birlikte, 011B ve 015B olarak tanımlanan ölçüm noktalarındaki tüm tel hazırlama makinaları da çalışıyor haldedir. Bu durum Çizelge 2.1'e göre farklılık oluşturmaktadır, arka bölüm çalışıyor iken makine ünitesinde alınan ölçümde, gürültü değeri üzerine arka birimin etkisini de göstermektedir. Bu değer 95,6 dB(A) olmuştur. Ölçüm noktası 011B'de gürültü seviyesi 96,1 $\mathrm{dB}(\mathrm{A}), 012 \mathrm{~B}$ 'de $87,9 \mathrm{~dB}(\mathrm{~A}), 015 \mathrm{~B}$ 'de $90,2 \mathrm{~dB}(\mathrm{~A}), 016 \mathrm{~B}$ 'de ise (ürünsüz çalışan makine) 89,9 $\mathrm{dB}(\mathrm{A})$ olmuştur. Son dört ölçümde $(011,012,015,016$ ile) aynı yerden ölçüm alınsa da genelde arka birimin devreye girmesi ile gürültü değerlerinin arttığı gözlenmiştir. Çizelgelerde, ölçüm mesafesi olarak verilen değerlere bakıldığında sırasıyla öncelikle 2 duvar, daha sonra 1 duvar olmak üzere sıkışık mekan da yer alan makinaya göre, açık alanı olduğu halde yerleştirilmiş olan bir makinanın ürettiği gürültü seviyesinin daha düşük olduğu görülmektedir. Buna sebep olarak, oluşan gürültünün daha hızlı bir şekilde yakın duvara teması ile yankılanması ve diğer gürültülerle karışması olarak açıklanabilir.

İşletmede makine ünitesi çalışmasında ortalama gürültü seviyeleri 86,1-101,6 $\mathrm{dB}(\mathrm{A})$ aralığında değişmiştir. Ölçülen 19 ortalama gürültü seviyesi değerinin sadece üç adedi 86,1 ; 87,$1 ; 89,5 \mathrm{~dB}(\mathrm{~A})$ olmuş, diğer 16 ölçüm noktasından ise 90,6-101,6 dB(A) ortalama gürültü seviyesi değerleri alınmıştır. Arka bölüm çalışmasında ölçülen 9 gürültü seviyesi ortalama 
değerleri ise 65,7-96.1 dB(A) aralığında olmuştur. Bu ölçümlerde 011B ölçüm noktasından en büyük ortalama gürültü değeri alındığı halde; bu bölüme uzak makine ünitesi, aynı bölümdeki iki tel hazırlama ünitesi ve parlatma birlikte çalışmaktadır. Resmi Gazete'de Yönetmelikte belirtilen "en yüksek maruziyet eylem değerleri $\left(\mathrm{L}_{\mathrm{EX}}, 8\right.$ saat $)=85 \mathrm{~dB}(\mathrm{~A})$ " değerlerinin üzerinde olup, ölçümlerin \%95'inin "maruziyet sınır değerleri $\left(\mathrm{L}_{\mathrm{EX}, 8} 8\right.$ saat $)=87 \mathrm{~dB}(\mathrm{~A})$ " nın üzerinde olması çalışan sağlığı açısından oldukça risklidir. Çünkü yönetmelik, "yeterli ölçüm ile tespit edilen haftalık gürültü maruziyet düzeyi, $87 \mathrm{~dB}(\mathrm{~A})$ maruziyet sınır değerini aşamaz" maddesine göre ölçüm değerleri, işletme içerisindeki ölçüm noktalarını da gösterdiğinden, işletmenin tamamın gürültü seviyesi açısından risk oluşturduğu söylenebilir.

Üretim tezgahlarının yapıları ve (ihmal edilen veya rutin) bakımlarındaki farklılıklar ortama yayılan gürültü seviyesini etkilemektedir. Üretim tezgahlarının tek veya çoklu çalışma hallerinde farklı gürültü seviyeleri elde edilmektedir. İşletmede ana gürültü kaynağı makina ünitesidir. İkinci seviyede ortama gürültü yayan hazırlık ve üretim sonrası bölümüdür ve bölümde çalışan tezgahlardan sırasıyla yüksek seviyeli gürültüden azalana doğru olmak üzere; parlatma, paketleme, tel çekme ve tel sarmanın, ana gürültü kaynakları olduğu belirlenmiştir. Ölçüm sonuçlarından gözlenen ana gürültü kaynağı olan makina ünitesine yaklaştıkça gürültü seviyesi artmaktadir.

Yüksek gürültü kaynakları için bölgesel ve ilave olarak gürültülü bölge mekanı için alınabilecek ses izolasyonu tedbirleri, çalışan sağlığı açısından yararlı olacaktır. Kulak tıkaçları ve ilave manşon kullanımı öncelikli tercih edilebilir, bu durumda en fazla ses azalmasının $50 \mathrm{~dB}(\mathrm{~A})$ 'yı geçmeyeceği bilinmelidir. Mevcut halde gürültüye sebep olan mekan oldukça büyüktür ve makine yerleşimleri çok sıkışıktır. Bu durumda bariyerlerin kullanımı çok yararlı olmayacaktır. Öncelikle mevcut birimin diğer birimlerden duvarlarla ayrıldığı ve duvarlar dahil ses yutucu malzemelerle kaplanması düşünülebilir. Diğer bir uygulama ise mevcut mekan olduğu halde iken her bir makinaya kısmi hücre uygulaması ile yine bir çözüm olarak verilebilir. Üçüncü bir uygulama önerisi ise makine ünitesinde bu son iki yöntemin birlikte kullanılmasıdır. Bariyerlerde en fazla elde edilebilecek gürültü kaybı 10 $\mathrm{dB}(\mathrm{A})$ olup, özellikle yüksek frekanslarda etkilidir. Endüstriyel tesislerde hücre uygulaması ile 10-40 dB(A) bir gürültü kaybı sağlanabilir (Özgüven, 1986).

$\mathrm{Bu}$ çalışmada üretim kaynaklı ortaya çıkan gürültünün çalışan sağlığı üzerine etkilerini azaltmak için çalışanlara sunulan donanımı, kendilerine verilen eğitime rağmen ve kendi sağlıklarıyla ilgili olmasına rağmen kullanma konusunda çekinceleri olması anlaşılabilir değildir. Gelişmiş ülkelerdeki çalışanların, kendi sağlıkları konu olduğunda ülkemiz çalışanından daha duyarlı oldukları görülmektedir. Ülkemizde konuyla ilgili çalışanlara yönelik eğitimlerin ciddiyetle yapılması gereği açıktır.

\section{Sonuç ve Öneriler}

Gürültünün insan sağlığı üzerine etkilerinde; fiziksel, fizyolojik, psikolojik ve performans üzerine olumsuz etkileri olduğu bilinmektedir. $\mathrm{Bu}$ nedenle çalışan sağlığ faaliyetine uygun düzenlemelerin yapılması gereklidir.

Sağlık açısından söz konusu işyeri değerlendirildiğinde; yeterli dinlenme aralarıyla çalışma süreleri düzenlenebilir, çalışanların dinlenmesi için ayrılan yerlerdeki gürültü düzeyinin düşük olması için gereken tedbirler alınabilir, hava yoluyla yayılan gürültünün perdeleme, kapatma, gürültü emici örtüler ve benzeri yöntemlerle azaltılması sağlanabilir ve yapı elemanları yoluyla iletilen gürültünün; yalıtım, sönümleme vb. yöntemlerle azaltılabilir. İşyerinde 
işveren tarafindan kulak koruyucu donanımlarının sağlandığı tespit edilmiştir. İşverenin işçilere gürültü hakkında gerekli eğitimi verdiği ve işçilerin özellikle kulak koruyucularını kullandıkları belirlenmiştir. İşçiler için işin yapısı gereği gürültü dışında aynı zamanda tozlu bir ortam oluştuğundan, kullanmaları gereken toz maskelerinin takılması konusunda işverenin denetimlerinin olduğu da gözlenmiştir. İşyerinin, çalışanları için üç ayda bir beş aşamalı bir sağlık kontrolü yapılmasını sağladığı da belirlenmiştir. 


\section{Kaynakça}

Alberti P.W., 1997. Noise and the ear. In; Kerr AG, Stephens D(Ed.). Scott-Brown's Otolaryngology Vol.2, London; Butterworth-Henemann Read Educational and Professional Publishing Ltd. Book, Chapter, 11, 1-34.

Angeletti I., Horner R. Luy L. 2015. Environmental and Social Management System Implementation Handbook. Metal Products Manufacturing. IFC, International Finance Corporation, World Bank Group. 15 April. Version 1.2.

Anonim, 2013. T.C. Çalışma ve Sosyal Güvenlik Bakanlığı. Çalışanların Gürültü İle İlgili Risklerden Korunmalarına Dair Yönetmelik. Resmi Gazete Tarih: 28/7/2013, Sayı: 28721.

Anonim, 18 Mayıs 2019. T.C. Çevre ve Şehircilik Bakanlığı, Çevre Yönetimi Genel Müdürlügü Gürültü ve Titreşim Kontrolü Şube Müdürlüğü, Çevresel Gürültü Ölçüm ve Değerlendirme Kılavuzu. "Bölüm 1: Gürültünün İnsan Sağlığg Üzerine Etkileri”. Ankara, 2011. Online; https://webdosya.csb.gov.tr/db/cygm/icerikler/cevresel-gurultuolcum-ve-degerlend-rme-klavuzu-20180209145104. pdf

Arıtan A.E., Tümer M., 2017. Elmas Telli Sayalama Makinesi Kullanılan Bir Doğaltaş Fabrikasında Ortam Şartlarının Değerlendirilmesi. Çukurova Üniversitesi Mühendislik Mimarlık Fakültesi Dergisi, 32(4): 185-192.

Ateş E., Alagöz M.G., 2018. Tarım Makinaları İmalatı Yapan Bir Firmada Gürültü Analizi. Karaelmas İş Sağlığı ve Güvenliği Dergisi, 2 (1): 13-22.

Cesva, 14 Şubat 2019. Acoustic Instruments. Cesva Instruments. S.1. Maracaibo, 6-08030, Barcelona, Spain. Online.https://www.cesva.com/en/products/sound-levelmeters/sc310/

Darpe A.K., 2015. Fundamentals of Noise; Department of Mechanical Engineering, IIT Delhi. Dec. 18.

Dedeler H., 2008. Bir İşletmede İşyeri Fiziksel Risk Etmenlerinin Çalışanların Sağlı̆̆ına Olan Etkisinin Saptanması ve Değerlendirilmesi. Trakya Üniversitesi, Sağlık Bilimleri Enstitüsü, Halk Sağlığı Anabilim Dalı, Edirne. (Yükssek Lisans Tezi). 
Erdoğan A., 2016. Denizli’de Üç Tekstil Fabrikasindaki Gürültü Düzeyinin Çalişanlar Üzerine Etkisi. T.C.Pamukkale Üniversitesi Tıp Fakültesi Halk Sağlığı Anabilim Dalı. Denizli. (Uzmanlık Tezi).

Güler Ç., Çobanoğlu Z., 1994. Gürültü. Sağlık Bakanlığı. Çevre Sağlığı Temel Kaynak Serisi No:19. Ankara, Kitap.

Kim B.S., Park J.Y., Lee Y.U., 2013. A Noise Generating Mechanism at Manufacturing Process of Metal Material Products- Focus on Small and Medium Size Enterprise. Journal of Korean Society of Mechanical Technology, 15(6): 925-930.

Olala F.A, Katiku N.T., 2012. Design of a Nail Making Machine Suitable For the Local Cottage Industry. Final year Project report. University of Nairobi. Project No. JMO/01/2012. May.

OSHA, 20 December 2016. Noise. Technical Manual. United States Department of Labor; Occupational Safety \& Health Administration. Section III. Chapter 5. Online, https://www.osha.gov/dts/osta/otm/new_noise/

Özce L., Ateş E., Bulduk İ., 2018. Bir İmalat Firmasında Gürültü Değerlendirilmesi. Mesleki Sağlık ve Güvenlik Dergisi (MSG), Türk Tabipleri Birliği. 18(67): 30-36.

Özgüven M.M., 2012. Kapalı Alanlarda Kullanılan Bazı Hasat Sonrası Tarım Makinalarının Gürültü Haritalarının İncelenmesi. Tekirdağ Ziraat Fakültesi Dergisi. 9(3): 45-53.

Özgüven N., 1986. Endüstriyel Gürültü Kontrolü. TMMOB, Makine Mühendisleri Odas1, Yayın No:118. Ankara. Kitap.

Porter N.D, Berry B.F., 1998. Noise and Nuisance Policy Health Effect Based Noise Assessment Methods: A Review and Feasibility Study. Department for Environment, Food and Rular Affairs. Sept.

Sağbaş A., Kahraman F., Eşme U., Özbek A., 2008. Tekstil İşletmelerinde Gürültü Ve Gürültünün Azaltılmasında Mühendislik Önlemler. Ç.Ü. Müh. Mim. Fak. Dergisi. 23(1): 181-187.

Singh L.P., Bhardwaj A., Deepak K.K., 2010. Occupational Exposure in Small and Medium Scale Industry with Specific Reference to Heat and Noise. Noise \& Health. 12(46): 3748. 
Soylu M., Gökkuş Ö., 2016. Endüstriyel Kaynaklı Gürültü Kirliliğinin Araştırılması ve Bir Tekstil Fabrikasında Uygulama Örneği. Erciyes Üniversitesi Fen Bilimleri Enstitüsü Dergisi Cilt 32, Sayı 2.

Wallace R. B., 1998. Maxy-Rosenau-Last Public Health \& Pretentive Medicine. Moller RA. Effects of the Physical Environment: Noise As a health hazard; Appleton \& Lange. 14th Edition. Stamford. USA, Book, 637-44.

Weinger M.B., Wiklund M.E., Bonneau D. J. G., 2010. Handbook of Human Factors in Medical Device Design. CRC Press. Taylor \& Francis Group. Book, 41.

Yavuz L., Ateş E., Bulduk İ., 2016. Bir İmalat Firmasında Gürültü Değerlendirilmesi. 1. Uluslararası İş Güvenliği ve Çalışan Sağlığı Kongresi. 6-2 Mayıs, 1(1): 244. 